\title{
EXPERT ASSESSMENT OF CONDITIONS FOR ACCREDITED QUALITY MANAGEMENT SYSTEM FUNCTIONING IN TESTING LABORATORIES
}

\author{
Joanna MYTYCH \\ Institute of Environmental Engineering, Polish Academy of Sciences \\ Mariusz J. LIGARSKI \\ Silesian University of Technology
}

\begin{abstract}
:
The quality management systems compliant with the ISO 9001:2009 have been thoroughly researched and described in detail in the world literature. The accredited management systems used in the testing laboratories and compliant with the ISO/IEC 17025:2005 have been mainly described in terms of the system design and implementation. They have also been investigated from the analytical point of view. Unfortunately, a low number of studies concerned the management system functioning in the accredited testing laboratories. The aim of following study was to assess the management system functioning in the accredited testing laboratories in Poland. On 8 October 2015, 1,213 accredited testing laboratories were present in Poland. They investigated various scientific areas and substances/objects. There are more and more such laboratories that have various problems and different long-term experience when it comes to the implementation, maintenance and improvement of the management systems. The article describes the results of the conducted expert assessment (survey) carried out to examine the conditions for the functioning of a management system in an accredited laboratory. It also focuses on the characteristics of the accredited research laboratories in Poland. The authors discuss the selection of the external and internal conditions that may affect the accredited management system. They show how the experts assessing the selected conditions were chosen. The survey results are also presented.
\end{abstract}

Key words: quality management system, ISO/IEC 17025:2005, accreditation, testing laboratory

\section{INTRODUCTION}

The management system in testing laboratories based on the ISO/IEC 17025:2005 has been widely described. A study published in Accreditation and Quality Assurance [1] presents the establishment of an accredited forensic genetics laboratory in Italy, which was done in compliance with the ISO/IEC 17025:2005. The paper discusses the difficulties that may be encountered in the above-mentioned laboratory. It particularly concerns the content-related problems associated with the test execution. The standard implementation contributed to the implementation of a defined work model enabling the researchers to improve the quality of the executed tasks. What is more, working in the accredited laboratory helped in the professional development of the employees and forced them to perform their tasks in compliance with the defined standards.

Another article [2] discusses the way how the accreditation was obtained and introduced in a university laboratory. It describes the encountered difficulties. It also indicates the advantages of the ISO/IEC 17025:2005 management system implementation and focuses on the time involvement and personnel requirements. The ISO/IEC 17025:2005 implementation was difficult due to a large number of students working in the laboratory. Thanks to the developed procedures, each person took the same measurement under the same conditions. The laboratory users also learnt that quality was more than a term. It translated itself into the work method. The authors state that the described quality system ought to be treated only as an example. The problems they had are in a way representative but they do not include all the difficulties that may be encountered by such an institution.

A similar issue was described in the publication on the laboratories located in education and research institutions [3]. The authors think that the recommended measures should help research laboratories to implement the management system in accordance with the ISO/IEC 17025:2005. However, it must be remembered that the involvement of particular persons is the key factor in the management system implementation. In the literature, there are also publications describing experiences of particular institutions in the quality management system based on the ISO/IEC 17025:2005 in terms of the content-related issues associated with the test execution $[4,5]$.

The above-mentioned literature overview confirms that many publications are devoted to specific laboratories and focus on the system implementation, analytical methodologies or other technical and technological aspects. The following article concentrates on selecting the conditions for functioning of the quality management system in accredited testing laboratories. It also focuses on the expert assessment (survey) of such conditions. 


\section{RESEARCH GROUP SELECTION}

The ISO/IEC 17025: General requirements for the competence of testing and calibration laboratories [6] is the basic standard describing the requirements to be met by a laboratory to obtain the accreditation for a defined scope of services. In many cases, it is a legal obligation for a laboratory to have the accreditation certificate to conduct the testing process in Poland. Such a requirement was imposed with the Environmental Protection Law (Journal of Laws 2001, No. 62, item 627, Act of 27 April 2001) [7] and Regulation of the Minister of Health of 12 November 2015 changing the regulation on safe conditions for ionizing radiation utilization for all medical exposure types (Journal of Laws 2013, No. 0, item 1015 as amended) [8]. More and more often, the national and international markets require accreditations for the rendered services. Consequently, having the accreditation becomes a common obligation. In Poland, the Polish Centre for Accreditation (PCA) grants the accreditations. The body was established on the basis of the Act on Conformity Assessment System of 30 August 2002 [9]. The PCA issues certificates of accreditation to institutions such as:

- testing laboratories,

- medical laboratories,

- calibration laboratories.

According to the PCA data of 8 October 2015, 1,213 testing laboratories with accreditations compliant with the ISO/IEC 17025:2005 (with valid certificates) functioned in
Poland. Figure 1 presents the number of laboratories in particular voivodeships. The biggest number of laboratories was observed in the Mazovia Voivodeship.

When analysing the available data, accredited laboratories can be classified according to the testing areas and substances/objects. The PCA indicated the areas in which the testing laboratories may function:

A. Acoustics and noise tests (including noise caused by vibrations).

B. Biological and biochemical tests.

C. Chemical tests, chemical analysis.

D. Clinical, medical and veterinary tests.

E. Electric and electronic tests.

F. Electromagnetic compatibility (EMC) tests.

G. Environmental engineering (environmental and climatic) tests.

H. Fire tests.

I. Forensic tests.

J. Mechanic and metallographic tests.

K. Microbiological tests.

L. Non-destructive testing tests.

M. Other tests.

N. Physical property tests.

O. Radiochemical and radiation (including nuclear) tests.

P. Sampling, laboratories accredited for sampling.

Q. Sensory tests.

The following figure presents the number of laboratories conducting tests/in the specific areas.

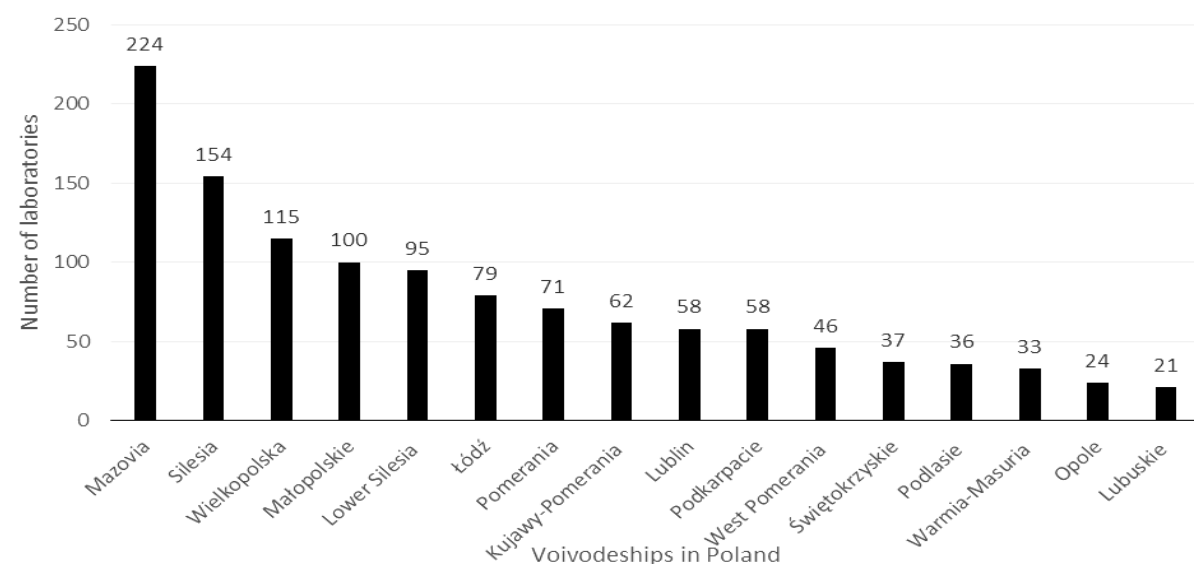

Fig. 1 Number of laboratories in particular voivodeships in Poland in 2015

Source: based on the data available on the PCA website of http://www.pca.gov.pl/akredytowane-podmioty/akredytacje-aktywne/ laboratoria-badawcze/ (PCA data as of 8 October 2015).

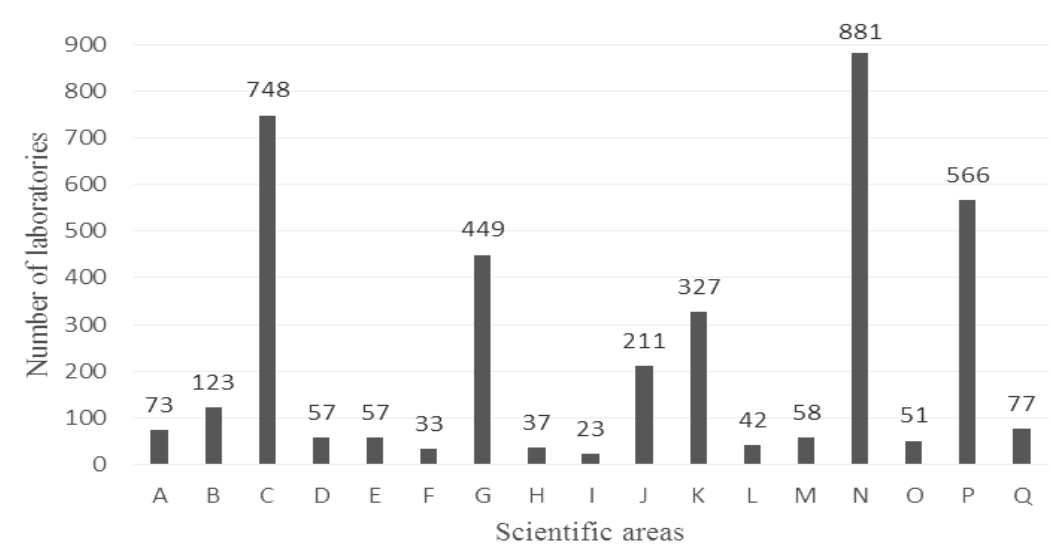


To sum up, most laboratories conducted tests in the following areas:

- N. Physical property tests (881 laboratories),

- C. Chemical research/tests, chemical analysis (748 laboratories),

- P. Sampling, laboratories accredited for sampling (566 laboratories),

- G. Environmental engineering (environmental and climatic) tests (449 laboratories).

The testing laboratories may also investigate the following objects:

1. Asbestos (including asbestos removal).

2. Chemicals, cosmetics, chemical products (including fertilizers and paints).

3. Wood.

4. Machines, production plants, equipment (including nuclear installations).

5. Furniture.

6. Biological objects and materials intended for research.

7. Fuels and lubricants.

8. Paper, cardboard, packaging materials.

9. Vehicles.

10. Environmental samples: air, water, soil, waste, sediments and wastewater.

11. Agricultural products (including animal fodder).

12. Glass and ceramics.

13. Personal protective equipment.

14. Textiles and leather, fabrics, yarn, clothing, and final products.

15. Electronic equipment (including software).

16. Medical equipment.

17. Optical equipment.

18. Military equipment, explosives, ammunition.

19. Building products, building materials, building objects.

20. Pharmaceutical products.

21. Construction materials and products (including metals and composites).

22. Electric, telecommunication and electronic products and equipment.

23. Other products.

24. Consumption products intended for people (including food).
25. Tobacco products.

26. Plastic and rubber products.

27. Toys, sport and recreational equipment.

To sum up, most laboratories investigated:

- 10. Environmental samples: air, water, soil, waste, sediments and wastewater (788; laboratories),

- 24. Consumption products intended for people (including food) (393 laboratories),

- 19. Building products, building materials, building objects (160 laboratories),

- 11. Agricultural products (including animal fodder) (147 laboratories.

\section{RESEARCH DIRECTIONS}

The analysis of the management system compliant with the ISO/IEC 17025 indicated the necessity to specify factors affecting the efficient functioning of the system.

The own work began with the detailed analysis of the requirements to be met by an accredited management system in a testing laboratory. The following factors were taken into account: the ISO/IEC 17025:2005 standard requirements, the PCA requirements (PCA is the institution granting accreditations for testing laboratories in Poland), customers' requirements, organizational structure, involvement of the employees and the highest management level. Such an approach enabled the authors to divide the conditions into internal and external ones.

The PCA requirements are included in the list of the external conditions affecting the management system due to the fact that PCA enlists detailed conditions to be met by a laboratory to obtain the accreditation certificate. The list concerns aspects such as the requirements to be fulfilled by laboratory managers and internal auditors at the X-ray laboratories or requirements focusing on the contract review. It was found out that the PCA requirements significantly affected the functioning of the quality management system.

At the first working stage, the condition list was long and consisted of more and less important aspects. A number of consultations was held to establish the final list of conditions divided into:

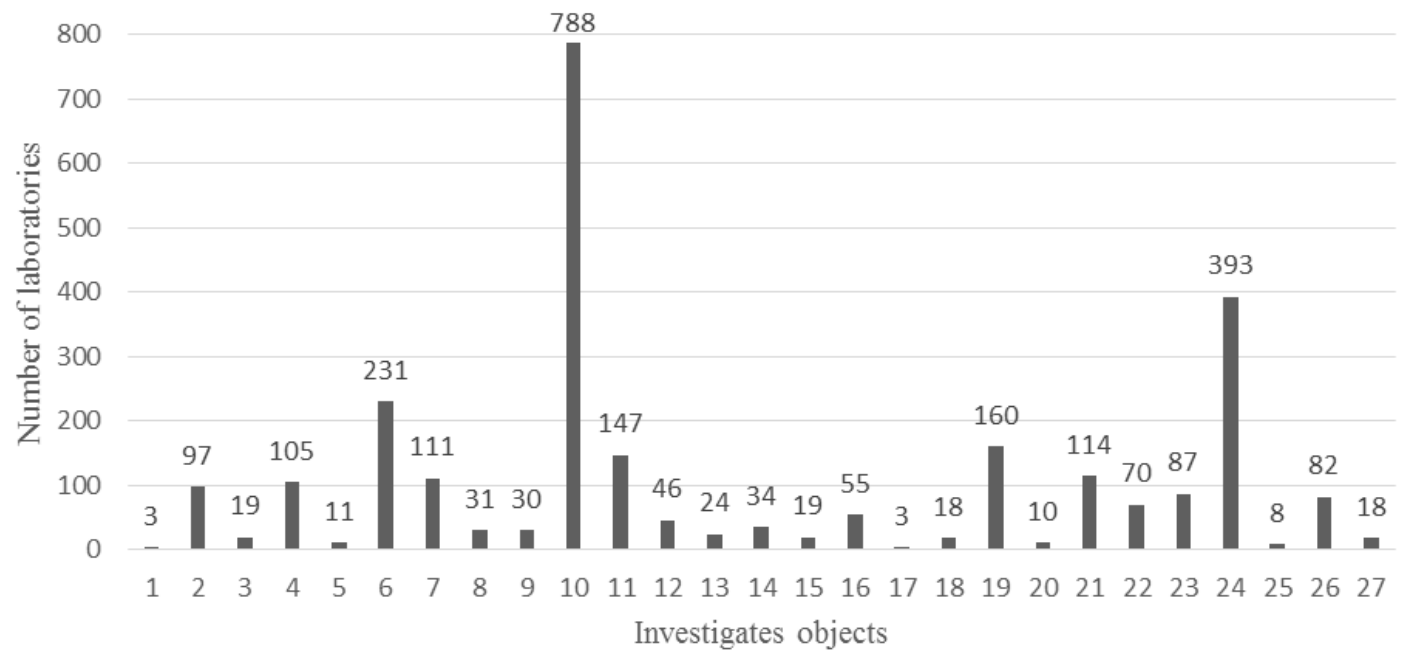

Fig. 3 Laboratories according to the investigated objects

Source: Based on the data available on the PCA website of http://www.pca.gov.pl/akredytowane-podmioty/akredytacje-aktywne/ laboratoria-badawcze/(PCA data as of 8 October 2015). 
External conditions, such as:

1. ISO/IEC 17025:2005 requirements as interpreted by ILAC, EA and PCA.

2. National regulations.

3. Market requirements.

Internal conditions, such as:

1. Internal structure of the unit providing the laboratory impartiality compliant with the ISO/IEC 17025:2005.

2. Resources of the management system functioning necessary for the required laboratory quality (e.g. personnel, room and environmental resources, equipment).

3. Awareness of the highest management level and personnel about the implemented management system.

4. Involvement of the highest management level and personnel in the proper management system functioning compliant with the ISO/IEC 17025:2005.

The detailed descriptions of the external and internal conditions are given in Tables 1 and 2.

The condition list was referred to a panel of experts to assess which of the discussed conditions were essential for the proper functioning of the accredited quality management system. It was decided to choose institutions associating the laboratories as they cooperate with one another and establish a common position for the entire group. In Poland, there are at least three associations which could enable such research. Additionally, the PCA employees were invited as another group assessing the management systems in laboratories. The experts were selected in relation to their competences and knowledge enabling them to decide which of the discussed conditions were essential and should be considered in further research. The experts were the persons knowing the quality management system compliant with the ISO/IEC 17025:2005 and having a longtime experience of working according to the ISO/IEC 17025:2005. The expert research was conducted among the PCA employees ( $\mathrm{min} .10$ persons) involved in the quality management systems. The employee selection was made by the Head of the PCA Department for the Laboratory Accreditation. It also concerned the board members of the following institutions (min. 5 persons from each organization): Pollab Club, Cluster of Research and Calibration Laboratories at the Lewiatan Association of the West Pomerania Employers in Szczecin and Polish Association of Emission Laboratories in Lublin.

The expert survey was carried out in February-June 2015. 10 and 4 surveys were received from the PCA and Polish Association of Emission Laboratories, respectively. 1 survey was received from the Pollab Club and from the Cluster of Research and Calibration Laboratories at the Lewiatan Association of the West Pomerania Employers. Tables 1 and 2 present the expert survey results.

Tables 1 and 2 show the list of conditions for the management system functioning, which was divided into external and internal aspects, and the obtained results of the expert survey. In order to select the most important conditions, the replies (one reply $=$ one point) indicating important and very important conditions were taken into account. Considering the number of replies, the conditions that received at least $85 \%$ of the experts' indications were selected for further research (criteria of important and very important). The results are given in Figures 4 and 5 .

Table 1

Expert research results on the external conditions

Rating scale

(no. of replies)

No External conditions

Unimportant Rather unimportant Rather important Important Very important

1. ISO/IEC 17025:2005 requirements as

interpreted by ILAC, EA and PCA

2. National regulations

3. Market requirements

4. Customer needs

Financial aspects (fees for accredita-

tions, assessment

5. in supervision, equipment mainte-

nance, etc.)

6xperience and knowledge

of external training companies

Continuous validation of competences

7. (assessment

in supervision)

Calibration of the measurement and

8. research equipment in the institutions accredited by the PCA

9. EU regulations, directives

10. National and international standards

$\begin{array}{ccccc}0 & 0 & 0 & 4 & 12 \\ 0 & 0 & 0 & 4 & 12 \\ 0 & 0 & 3 & 7 & 6 \\ 0 & 0 & 3 & 4 & 9\end{array}$

Source: Own research. 
Table 2

Expert research results on the internal conditions

Rating scale

(no. of replies)

Internal structure of the unit provid-

ing the laboratory impartiality com-

pliant with the PN-EN ISO/IEC

17025:2005

Resources of the management system functioning necessary for the

2. required laboratory quality (e.g. personnel, room and environmental resources, equipment)

Awareness of the highest manage-

3. ment level about the implemented management system

Awareness of the personnel about

4. the implemented management

system

Involvement of the highest manage-

5. ment level in the proper manage-

ment system functioning compliant with the PN-EN ISO/IEC 17025:2005

Involvement of the personnel in the

proper management system

. functioning compliant with the PN-EN ISO/IEC 17025:2005

7. Appropriate preparation of the employees for the assigned tasks

8. Improvement of the employees'

knowledge

Employee competence assessment

9. to continuously improve the ren-

dered services

Systematic assessment of the adopted research methods as an essential factor necessary for the required

10. functioning quality (proficiency testing, inter-laboratory comparisons, inter-method research) to continuously provide research quality

11. Understanding the benefits of the accreditation

Internal communication

12 in the laboratory in relations to the management system

13. Other: research method validation/ verification

14. Other: assurance of the result quality, research quality steering

0

0

0

Source: Own research. 


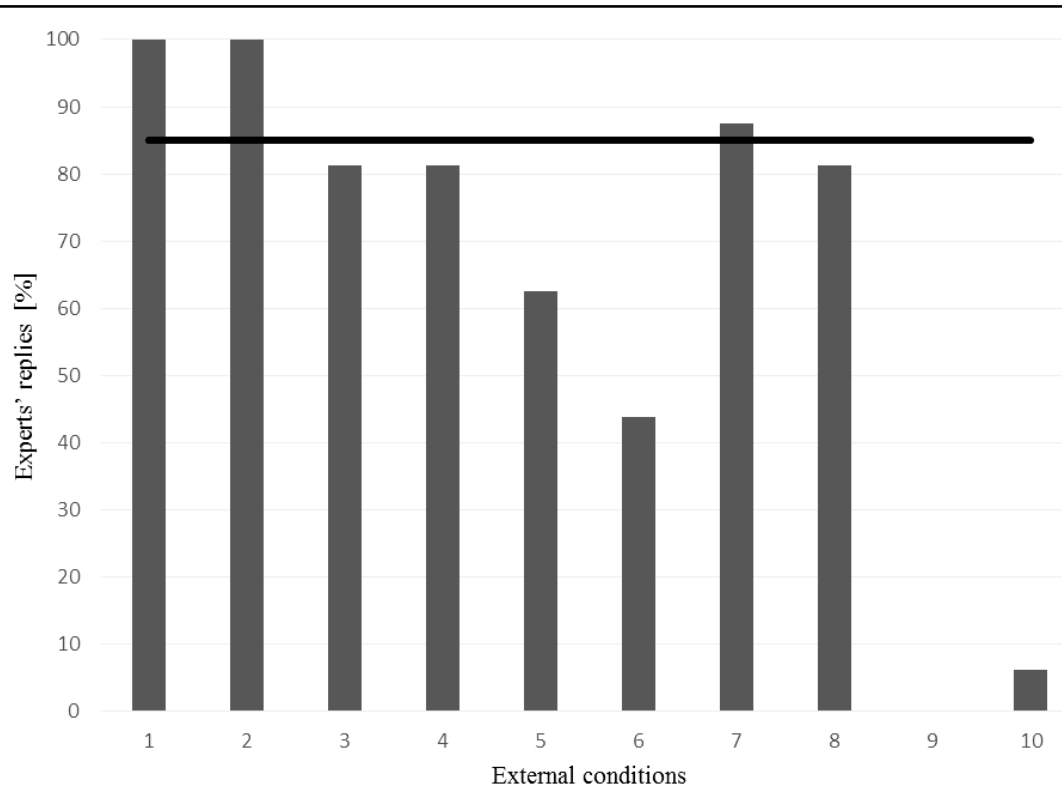

Fig. 4 Experts' replies concerning external conditions Source: Own research.

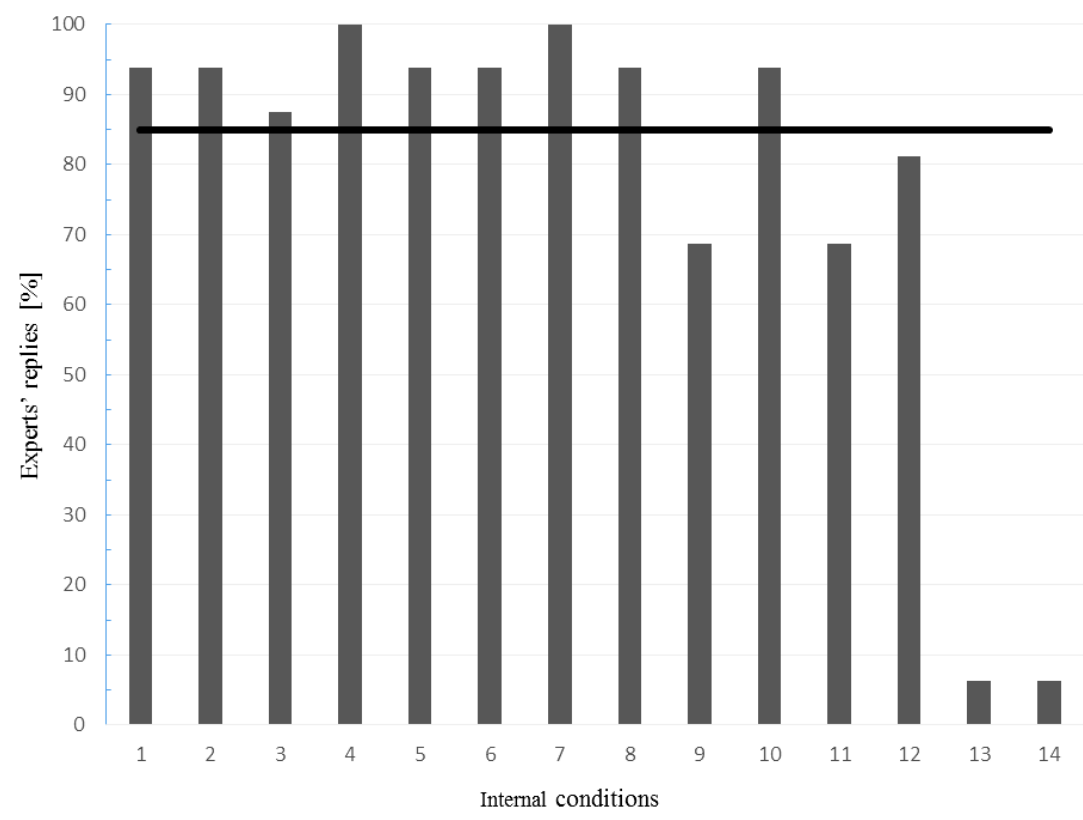

Fig. 5 Experts' replies concerning internal conditions Source: Own research.

The results indicate the most important external conditions:

1. ISO/IEC 17025:2005 requirements as interpreted by ILAC, EA and PCA

2. National regulations

3. Continuous validation of competences (assessment in supervision).

The following internal conditions were the most important:

1. Internal structure of the unit providing the laboratory impartiality compliant with the ISO/IEC 17025:2005.

2. Resources of the management system functioning necessary for the required laboratory quality (e.g. personnel, room and environmental resources, equipment).

3. Awareness of the highest management level about the implemented management system.
4. Awareness of the personnel about the implemented management system.

5. Involvement of the highest management level in the proper management system functioning compliant with the ISO/IEC 17025:2005.

6. Involvement of the personnel in the proper management system functioning compliant with the ISO/IEC 17025:2005.

7. Appropriate preparation of the employees for the assigned tasks.

8. Improvement of the employees' knowledge.

9. Systematic assessment of the adopted testing methods as an essential factor necessary for the required functioning quality (proficiency testing, inter-laboratory comparisons, inter-method research) to continuously provide the testing quality. 
At the further research stage, a survey based on the expert survey results will be prepared. It will include only the conditions qualified as the most important ones. The elaborated survey will be sent to Polish testing laboratories. Its target will be the assessment of the management system functioning in the organizations to be done by the laboratories. The further research will also enable the comparison of the conditions for the management system functioning from the viewpoints of experts and laboratories. The obtained results of the survey conducted among the accredited testing laboratories will help to assess the functioning of the management system in an accredited testing laboratory and to develop a model laboratory.

\section{SUMMARY AND CONCLUSIONS}

The objective of this study was to select conditions affecting the proper functioning of the management system according to the ISO/IEC 17025:2005. To achieve that, the current situation in Poland concerning the number of the testing laboratories and their testing areas has been analysed. In Poland, there were 1,213 accredited laboratories (as of 8 October 2015) conducting investigations in various areas, such as physical property tests, chemical tests, chemical analysis; sampling, laboratories accredited for sampling; or environmental engineering (environmental and climatic) tests. In Poland, the laboratories most often investigate: environmental samples (air, water, soil, waste, sediments, and wastewater); consumption products intended for people (including food); building products, materials and objects; and agricultural products (including animal fodder).

The article divides the conditions for the functioning of the accredited quality management system into the external and internal ones. The designated conditions were assessed by the experts from the selected group (the PCA employees and board members of the Pollab Club, the Cluster of Research and Calibration Laboratories at the Lewiatan Association of the West Pomerania Employers in Szczecin and the Polish Association of Emission Laboratories in Lublin). The survey helped to select the conditions with major influence on the quality management system functioning.

The experts selected the most important conditions (i.e. three external and nine internal ones). The findings confirm that the efficient functioning of the management system depends on the organization itself (internal conditions) to a larger extent. It is not only the number but also the type of conditions that significantly determines the institution activity. The internal conditions mainly concern the laborato- ry functioning resources, as well as awareness, involvement and proper knowledge of the highest management level and personnel. The type of the selected conditions indicates that meeting the ISO/IEC 17025:2005 and PCA requirements depends on the particular institution and its involvement in the improvement of the management system. Even though the implemented PCA requirements may seem burdensome and increase the bureaucracy (according to the expert assessment), the laboratories themselves arrange the implemented management system, which is directly translated into the indicated conditions for the functioning of the management system.

\section{REFERENCES}

[1] U. Ricci, "Establishment of an ISO 17025:2005 accredited forensic genetics laboratory in Italy", Accred Qual Assur, vol. 19, iss. 4, pp 289-299, June, 2014.

[2] K, Hullihen, V. Fitzsimmons, M. R, Fisch: "Establishing an ISO 17025 Compliant Laboratory at a University" in Proceedings of The 2008 IAJC-IJME International Conference, Paper \# 059, IT 305, 2008, pp. 1-15

[3] I. H Grochau, C. Schwengber: "A process approach to ISO/IEC 17025 in the implementation of a quality management system in testing laboratories", Accred Qual Assur., vol. 17 iss. 5, pp. 519-527, 2012.

[4] A. Kessler, L. Siekmann, C. Weykamp, W.J. Geilenkeuser, O. Dreazen, J. Middle, G. Schumann, "External Quality Assessment Scheme for reference laboratories - review of 8 years' experience", Clin Chem Lab Med, vol. 51, iss. 5, pp. 997-1005, 2013.

[5] B. Breustedt, U. Mohr, N. Biegard, G. Cordes, "Quality management system and accreditation of the in vivo monitoring laboratory at Karslruhe Institute of Technology", Radiat Prot Dosimetry, vol. 144, pp. 95-107, 2010.

[6] General requirements for the competence of testing and calibration laboratories. ISO/IEC 17025:2005, 2005

[7] Environmental Protection Law (Journal of Laws 2001, No. 62, item 627, Act of 27 April 2001) (in Polish)

[8] Regulation of the Minister of Health of 12 November 2015 changing the Regulation on safe conditions for ionizing radiation utilization for all medical exposure types (Journal of Laws 2013, No. 0, item 1015 as amended). (in Polish)

[9] Act on Conformity Assessment System of 30 August 2002 (in Polish)

\footnotetext{
mgr inż. Joanna Mytych

Institute of Environmental Engineering

Polish Academy of Sciences

ul. Skłodowskiej-Curie 34, 41-819 Zabrze, POLAND

tel. +4832 2716481

e-mail: Joanna.Mytych@ipis.zabrze.pl

dr hab. inż. Mariusz J. Ligarski, prof. Pol. Śl.

Silesian University of Technology

Faculty of Organization and Management

Institute of Production Engineering

ul. Roosevelta 26, 41-800 Zabrze, POLAND

e-mail: mariusz.ligarski@polsı.pl
} 